Available online at www.jmle.org

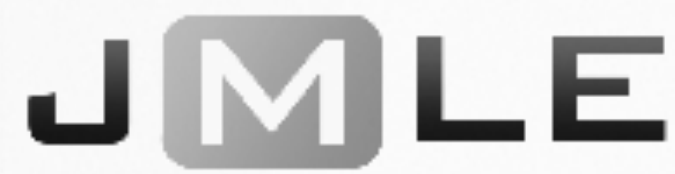

The National Association for Media Literacy Education's

Journal of Media Literacy Education 9 (1), 36 - 63

\title{
Adapting New Media Literacies to Participatory Spaces: Social Media Literacy Practices of Multilingual Students
}

\author{
Osman Solmaz \\ Dicle University, Turkey
}

\begin{abstract}
Approaching the new media literacies as social practices through the lens of Participatory Culture Framework, the present study adapted new media literacies to online social networks and examined the social media literacy practices of international graduate students (IGSs). The data was collected through an online survey of 90 IGSs, semistructured interviews with 13 volunteers, and social media data of these volunteers. Quantitative and qualitative analyses of the data revealed that IGSs engage in various social media literacy practices through the employment of multimodal tools and resources afforded by social networking sites despite differences across a multitude of literacies. Based on the findings, Social Media Literacies are proposed as a set of socioliteracy practices that are essential for navigation and participation in online diverse networks.
\end{abstract}

KEYWORDS: social media literacies, participatory culture, international graduate students, new media literacies

Individuals who engage in digital participatory spaces (e.g., online social networks) are assumed to possess certain abilities in order to navigate through various sociocultural contexts and audiences that involve recognizing, processing, negotiating, and producing multiple modes, utilizing diverse language resources, and performing novel ways of meaning-making (Jenkins, 2006; New London Group, 1996). This non-singular view of literacies is often interchangeably referred to as multiliteracies, digital literacies, new literacies, (new) media literacies (Dawson and Siemens, 2014), or transliteracies (Fleming, 2013). They are understood not as definitive and autonomous skills, but as social practices in which one engages for the sake of communication. Offering insights from a communication and media studies perspective, Jenkins (2006) and Jenkins, Purushotma, Clinton, Weigel, and Robison (2006) conceptualize the socio- 
literacy practices that are necessary to be part of online communities through the lens of 'convergence culture' and 'participatory culture.' The first term refers to the flows of content and the migratory behavior of media audiences across multiple media platforms. Although convergence occurs across commercial products, Jenkins himself notes that the content is not limited to certain types of materials, and that our lives, memories, relationships, and desires also flow across multiple media platforms. He states that, "Being a lover or a mommy or a teacher occurs on multiple platforms. Sometimes we tuck our kids into bed at night and other times we Instant Message them from the other side of the globe" (Jenkins, 2006, 17). The latter term involves the sharing and presentation of converged content in participatory settings online. The emphasis is placed on community involvement rather than individual expression as well as social abilities which are developed through collaboration and networking.

The features of online participatory culture are defined by Jenkins et al. (2006) as relatively low barriers to artistic expression and civic engagement, support for creating and sharing one's creations, informal mentorship, a sense of social connection, and a belief of the importance of the contributions. Jenkins et al. (2006) list eleven new media literacies (NMLs) as prerequisite to being active, creative, and ethical participants in participatory culture: Play, Simulation, Performance, Appropriation, Multi-tasking, Distributed Cognition, Collective Intelligence, Judgment, Transmedia Navigation, and Networking.

\section{Towards Social Media Literacies}

Based on these criteria, it can be argued that online social networks are sites of participatory culture where users create, contextualize, and share content in a setting where there is almost no barrier for artistic expression and civic engagement. Informal mentorship is also available in social networking sites (SNSs) as users who are experienced in a certain topic or practice in a network share their knowledge with novices in a setting where novices and experts can often change roles.

One of the goals of the present study is to understand in what levels international graduate students (IGSs) engage in these literacy practices in order to increase their involvement in participatory settings. Since the NMLs that Jenkins and his colleagues propose mainly address youth and target interactive new media spaces in general, there may be a need for these literacies to be reinterpreted for adults in global SNS contexts. Recognizing this need, Ahn (2013) employed social learning analytics to observe NMLs on Facebook. By collecting data using a Facebook application developed for his project, he utilized factor analysis and regression models to show the correlation between Facebook members' online activity with their NMLs. He found that literacies of Negotiation, Appropriation, Networking, and Transmedia Navigation were particularly salient across Facebook activities, while literacies of Play, Judgment, and Multi-tasking were less relevant. The significance and contribution of the current study comes from its clarification of what kinds of activities on Facebook relate to which specific socio-literacy practices. Similarly, Dawson and Siemens (2014), who employed learning analytics as well, outlined possible indicators and 
metrics for each literacy for the purpose of evaluating multiliteracies. They provided examples for artifacts produced and associated with each practice within larger digital media contexts. Revealing and mapping users' content patterns based on their traces in the websites offers valuable perspectives for understanding NMLs in participatory contexts. However, it is important to note that approaches like these "draw heavily on the most obvious and accessible features of the information architecture of the website itself, trading scale off against nuance and complexity" (Burgess and Green, 2009, 7).

The interpretation of NMLs in SNS context through qualitative research methods can provide further insights regarding engagement in these socio-literacy practices, as well as an understanding of social connections and conflicts between SNS users. Not everyone may share the same cultures-of-use (Thorne, 2003) (i.e., way of adopting and using a particular technological tool), thus the interpretation of NMLs through international participants' SNS uses can show how these literacies are practiced in culturally diverse spaces. International graduate students and their experiences are worth addressing in their own right, as they often have different cultural and educational backgrounds that might affect their overall experiences. In addition, not only are these multilingual students exposed to diverse sociocultural traditions in face-to-face and online contexts as they experience a transnational mobility, but they also have relatively rich multilingual repertoires, which contribute to the maintenance of culturally rich online communities evolving around multilingual literacy practices. The scholarship addressing the social media practices of international graduate students is currently limited to a few studies (e.g., Chen, 2013).

\section{The Assessment of New Media Literacies}

Beyond the functions of NMLs, there is also a need to develop an assessment tool to measure the media literacy capabilities of individuals. Exploring the relevant literature, we see a number of works focusing on this issue. For instance, Literat (2014) has formed a self-report assessment tool for NMLs by developing a test with 60 items (5 items for each NML). She found a strong relationship between NMLs and her respondents' participation in Web 2.0 platforms. Based on feedback from her participants, she suggested the development and use of distinct versions of the questionnaire for different age groups, as her respondents (average age $=33.7$ ) commented that the statements were youth-focused. She also recommended a condensed version of the survey.

Young (2015), who assessed NML levels of social work students and educators, also received a similar comment as one of his participants reported that the statements were related to pop culture or younger people. Even though Young (2015) successfully replicated the reliability of 9 NMLs, he suggested that a qualitative research design could aid in the development of better questions. In a similar vein, Dawson and Siemens (2014) argued that a more nuanced and diverse approach could be more effective. Similar to these recommendations, the present study suggests that a NML tool should be developed for understanding and assessing literacies in particular new media spaces, such as SNSs. 
In sum, the notion and processes of convergence and participatory cultures are significant since they lead users to generate heterogeneous discourses and create diverse communities in which various language uses, genres, media resources, and converged contents co-exist and are shared (Sharma, 2012). Jenkins et al.'s (2006) participatory culture framework and suggested NMLs can be invaluable for a nuanced interpretation of participation in new media spaces. Since the dynamics and affordances of various participatory spaces (e.g., YouTube, Facebook) can vary greatly, investigating the functions of NMLs for efficient participation can yield greater insights if they are reinterpreted within relevant contexts. Along with the endorsement of Jenkins et al.'s (2006) ecological approach, which lays out the interrelationship among different technologies, certain technologies (such as SNSs) can be categorized and examined on their own merits due to their increasing number and popularity across various age groups and geographical spaces. Since such networks allow other Web 2.0 tools to circulate within these spaces, dealing with SNSs often requires taking an ecological stance as well.

Guided by such considerations, this study claims that understanding the functions NMLs serve in SNS context, as well as how second language learnersmultilingual students in particular - use them for participation, is important and has theoretical and pedagogical contributions. For this purpose, by drawing from new media studies and participatory culture framework, this study aims to highlight the digital practices of multilingual students, and to what extent and how they employ NMLs in this new media ecology while experiencing a transnational mobility. In order to address that, the following research questions are formulated:

1. What are the reported new media literacy levels of international graduate students in the United States?

2. What kinds of social media literacy practices do multilingual students engage in online social networks?

\section{Participants}

\section{Research Methodology}

In order to address the research questions above, 90 international graduate students (IGSs), who are enrolled in Master's or doctoral programs at higher education institutes across the United States and actively use at least one SNS, participated in the study. Male participants were $38 \%(n=34)$ of the study, while females were $62 \%(n=56)$. The average age of the participants, who were between 22 and 49 years old, was 26.8. Sixty-one (68\%) of the informants were enrolled in a doctoral program and $29(32 \%)$ of them were either Master of Arts or Master of Science students. The national backgrounds of the participants were widely distributed across the globe. Almost half of the participants (42\%) noted that their duration of stay in the U.S. was more than three years $(n=38)$. The other $42 \%$ of the students indicated that they spent between 1 to 3 years for their graduate studies in the U.S., while 14 individuals (16\%) reported that they had been in the U.S. for less than a year at the time of data collection. For semi-structured interviews and analysis of social media data, 13 volunteers from the survey 
participants were selected based on their new media literacy scores, which were calculated through their responses in the online survey, which also asked participants for their field of study, home country, gender, pursued degree, and length of stay, respectively.

A majority of the participants $(93 \%, n=84)$ reported that they have been using Facebook. Similarly, other SNSs addressing a wider audience such as Google $+(57 \%, n=51)$, Twitter $(51 \%, n=46)$, and Instagram $(34 \%, n=31)$ were popular among IGSs. A high number of participants had accounts on professional SNSs such as LinkedIn $(67 \%, \mathrm{n}=60)$ and Academia.edu $(39 \%, \mathrm{n}=35)$. A limited number of participants indicated in the open-ended section of the survey that they used educational SNSs such as Edmodo and Ning, the professional SNS ResearchGate, instant communication applications such as Line, Whatsapp, KakaoTalk, Snapchat, WeChat, QQ, and Path, as well as certain local SNSs including Tuenti (Spain), VKontakte (Russia), Odnoklassniki (Russia), renren (China), Fanfou (China), Weibo (China), StudiVZ (Germany). Based on the results, it is clear that Facebook, the most commonly used social networking platform, is also the most popular SNS used by IGSs. Because of this, the majority of the examples provided in the results section come from the Facebook data of the participants.

\section{Data Collection}

A mixed-methods approach was followed in the present study and the data triangulation was ensured through an online survey, semi-structured interviews (between 45-min to 90-min), and social media data. The data collected was blended and included both screen-based and user-based data, which are considered as two main sites of data collection in new media sociolinguistics by Androutsopoulos (2013). Screen-based data in the current study are the social media data produced by IGSs and collected by the researcher, while user-based data are collected through the researcher's contact with IGSs through an online survey and semi-structured interviews.

The online survey was developed by the author and consisted of questions in an open-ended format and Likert-scale statements (Cronbach's Alpha for reliability analysis was .825). Piloting of the survey was conducted for the purpose of overcoming potential ambiguities, misinterpretations, and technical improvements. Semi-structured interviews were made with 13 volunteers from the survey respondents in order to draw a more comprehensive picture of the social media literacy practices of the participants.

For the collection of screen-based data (i.e., social media data of the participants), two of the data sampling categories from Computer-Mediated Discourse Analysis (CMDA) framework (Herring 2004) were chosen: data sampling by individual and data sampling by time. Thirteen interviewees' SNS data and posts between the beginning of 2013 and the end of 2014 in the data collection process were included. The data, which largely included participants' profile pictures, cover photos, and posts they shared, covered a minimum of one year for each participant and as long as two years for some participants. The 
number of posts/status updates that was collected was 690, averaging 43 activities per participant.

The data were collected through a cyclical procedure, which is a comprehensive way of collecting data involving both screen- and user-based data (Androutsopoulos 2013). As the name suggests, the data collection process did not necessarily follow a linear procedure, instead the steps included in the procedure were often recursive: Preliminary observation and piloting, administration of the survey, contact with volunteers for interviews, collection of social media data, and semi-structured interviews.

\section{Approach to Data Analysis}

Computer-Mediated Discourse Analysis (CMDA) (Herring 2001, 2004) was followed as the methodological framework since it allows the flexibility of choosing a set of best suited methods to the data and research questions, and offers a methodological toolkit through which researchers can follow an empirical analysis and report findings of the collected computer-mediated discourse. Applying methods adapted from disciplines such as linguistics and communication, CMDA's methodology involves qualitative and/or quantitative analyses.

Quantitative and qualitative analyses of the collected data in the present study followed a cyclical analysis procedure, similar to the data collection process. Quantitative and content analyses of the online survey were followed by the qualitative analyses of social media data and semi-structured interviews. Qualitative analysis was "a progressive process of sorting and defining and defining and sorting those scraps of collected data" (Glesne 2010, 194) through which a thematic organizational framework was created. Following the coding and organization of the data, connections and comparisons within and between themes were observed and an outline of the findings was produced for the interviews. Regardless of the preset categories that emerged from the interviews, qualitative aspect of social media data analysis was performed both inductively and deductively. Inductive analysis at this stage allowed the author to run a separate analysis and reveal themes similar and different to the analysis of the interviews. Following the inductive analysis, themes from two analyses were woven together. As a result, even though the content analysis started with an etic (researcher-outsider) focus, the reflexive and cyclical process of analysis led to some unexpected emic (participant-insider) questions and incidents that were important for the research.

\section{Findings}

First, I report data from the survey, followed by qualitative analysis of screen-based data. Designed after Jenkins et al.'s (2006) definitions of NMLs, the online survey included 11 Likert-type items corresponding to, and designed to measure, self-assessment of the 11 NMLs of (1) Play, (2) Simulation, (3) Performance, (4) Appropriation, (5) Multi-tasking, (6) Distributed Cognition, (7) Collective Intelligence, (8) Judgment, (9) Transmedia Navigation, (10) Networking, and (11) Negotiation (Table 1). The mean score on a 5-point scale 
ranging from 1 (Very Poor) to 5 (Very Good) for the Likert-scale was found to be 3.82. A higher mean score represents a higher rate of agreement with the associated statement. Thus, as shown in Table 1, participants of this study reported that their NMLs were above 3 (Average) and close to a mean score of 4 (Good).

Table 1. Reported New Media Literacies of the Online Survey Participants

\begin{tabular}{|c|c|c|c|}
\hline \# & Statement & M & SD \\
\hline 1 & I can play and experiment with resources in my surroundings as a form of problem-solving. & 3.76 & 0.83 \\
\hline 2 & I can interpret and construct dynamic models (simulations) of real world processes. & 3.40 & 0.88 \\
\hline 3 & I can display various aspects of my identity in social networking platforms. & 3.70 & 0.93 \\
\hline 4 & I can meaningfully sample and remix media content. & 3.34 & 1.05 \\
\hline 5 & I can scan my environment and shift focus onto salient details on a regular basis. & 3.70 & 0.87 \\
\hline 6 & I can interact meaningfully with digital tools that expand my mental capacities. & 3.76 & 0.84 \\
\hline 7 & I can collect information and compare notes with others towards a common goal. & 4.06 & 0.87 \\
\hline 8 & I can evaluate the reliability and credibility of different information sources. & 4.12 & 0.79 \\
\hline 9 & I can follow of the flow of stories and information across multiple modes and genres. & 4.03 & 0.79 \\
\hline 10 & I can successfully manage to balance my network in diverse social networking contexts. & 3.73 & 0.98 \\
\hline 11 & I can respect multiple perspectives, cultures, and understand and follow alternative norms. & 4.44 & 0.58 \\
\hline & Total & 3.82 & 0.85 \\
\hline
\end{tabular}

The statistical data showed that the highest literacy participants reported to have was Negotiation $(\mathrm{M}=4.44)$. The data also revealed that IGSs reported having NMLs of Judgment $(\mathrm{M}=4.12)$, Collective Intelligence $(\mathrm{M}=4.06)$, and Transmedia Navigation $(\mathrm{M}=4.03)$ all above the mean score of 4 (Good). The lowest NML that was reported was Appropriation $(M=3.34)$, while Simulation $(M=3.40)$, Performance $(\mathrm{M}=3.70)$, and Multi-tasking $(\mathrm{M}=3.70)$ were also comparatively lower. Nonetheless, all of the reported NMLs, including the Appropriation, were above the average mark $(\mathrm{M}=3)$.

Since the social media data of the participants who only took part in the semi-structured interviews were collected and analyzed, the demonstration of this group's reported NMLs separately is important to assess their qualification as representatives of the online survey participants. As shown in Table 2, the mean score of the 5-point Likert-scale responses of the interviewees was 3.72. Similar to the online survey participants, Negotiation $(M=4.50)$ was the highest NML, whereas Simulation $(M=3.12)$ was the lowest. Based on a statistical comparison of the reported NMLs of both online survey participants and the interviewee group, it can be argued that the 13 students who were interviewed adequately represent the online survey group in terms of the NMLs that were possessed by IGSs. Following the quantitative results of IGSs' NMLs, a number of cases from SNS data in which NMLs are displayed are presented below. Even though the literacies that were observed in SNS data are given under a particular category (i.e., Appropriation), it is important to note that more than one literacy is often employed in the participation in SNSs. 
Table 2. Reported New Media Literacies of the Interviewees, Online Survey Participants, and Mean Difference between Groups

\begin{tabular}{|c|c|c|c|c|}
\hline \# & Statement & I & OSP & MD \\
\hline 1 & $\begin{array}{l}\text { I can play and experiment with resources in my surroundings as a form of problem- } \\
\text { solving. }\end{array}$ & 3.68 & 3.76 & -0.08 \\
\hline 2 & I can interpret and construct dynamic models (simulations) of real world processes. & 3.12 & 3.40 & -0.28 \\
\hline 3 & I can display various aspects of my identity in social networking platforms. & 3.93 & 3.70 & +0.23 \\
\hline 4 & I can meaningfully sample and remix media content. & 3.56 & 3.34 & +0.16 \\
\hline 5 & I can scan my environment and shift focus onto salient details on a regular basis. & 3.56 & 3.70 & -0.14 \\
\hline 6 & I can interact meaningfully with digital tools that expand my mental capacities. & 3.68 & 3.76 & -0.08 \\
\hline 7 & I can collect information and compare notes with others towards a common goal. & 3.68 & 4.06 & -0.38 \\
\hline 8 & I can evaluate the reliability and credibility of different information sources. & 3.87 & 4.12 & -0.25 \\
\hline 9 & $\begin{array}{l}\text { I can follow of the flow of stories and information across multiple modes and } \\
\text { genres. }\end{array}$ & 3.93 & 4.03 & -0.10 \\
\hline 10 & $\begin{array}{l}\text { I can successfully manage to balance my network in diverse social networking } \\
\text { contexts. }\end{array}$ & 3.50 & 3.73 & -0.23 \\
\hline 11 & $\begin{array}{l}\text { I can respect multiple perspectives, cultures, and understand and follow alternative } \\
\text { norms. }\end{array}$ & 4.50 & 4.44 & +0.06 \\
\hline & Total & 3.72 & 3.82 & -0.10 \\
\hline
\end{tabular}

\section{Social Media Literacy Practices of Participants}

\section{Play, Simulation, and Performance}

Play is described as "the capacity to experiment with one's surroundings as a form of problem-solving" (Jenkins et al., 2006, 22). While the concept of play is largely interpreted within the context of digital games, it is also noted that engagement coming from the play can also exist in professional lives in different forms including as a form of problem-solving. The 90 IGSs in this study had a mean score of 3.76 and this literacy ranked in the middle of all others.

Play as an NML in social media can be interpreted both within and beyond the educational scope of the original concept. Thomas (all of the participants names are pseudonyms), a fourth-year German PhD student in Economics, is seen engaged in a playful activity in his social networking page. Receiving four spam e-mails about automatically earning money at home within two hours in the same 
day, Thomas interpreted his surroundings as a form of problem-solving by putting a playful effort on the analysis of the e-mails. Guided by his willingness and motivation, and making use of his professional background, he created a table where he listed all the variables across the four e-mails. Then, he continued his playful experiment by speculating on the potential academic and economical motivations of the spammers. During the interview, Thomas noted that the spams were originally in German and he translated the vocabulary in the table into English. As seen in Figure 1, Thomas' language choice (English) corresponded with the most commonly spoken language among his colleagues who made up the main group of people he addressed. Thus, by performing and sharing this playful remix, Thomas not only displayed his professional skills, but also exhibited his capacity of experimentation with his surroundings, random spam e-mails in this case.

I noticed today that four spam emails I received within 2 hours telling me about awesome ways some grandma uses to make money automatically and from home had almost identical designs, with a few phrases and numbers differing between all of them. I've summarized the differences between the offers in a comparison table, and am now wondering whether the unknown spammers are running some kind of elaborate $A / B$ testing, or whether they actually want to estimate my time/money/difficulty/quality trade off preferences

\begin{tabular}{|l|r|r|r|r|}
\hline & \multicolumn{1}{c}{ A } & \multicolumn{1}{c}{ B } & \multicolumn{1}{c}{ C } & \multicolumn{1}{c|}{ D } \\
\hline Grandma's income & 5000 EUR & 8369 EUR & 8369 EUR & 8000 EUR \\
\hline Daily work hours & 1 to 2 & 1 to 3 & 2 to 3 & 1 to 3 \\
\hline Grandma's Age & 61 years & 65 years & 65.5 years & 64 years \\
\hline Grandma worked for & 42 years & 21 years & 45 years & 21 years \\
\hline Income after 3 months & 11,500 EUR & 11,500 EUR & 11,500 EUR & 12,541 EUR \\
\hline Income after 6 months & 18,452 EUR & 18,126 EUR & 18,745 EUR & 20,225 EUR \\
\hline Income after 1 year & 30,750 EUR & 30,450 EUR & 25,500 EUR & 31,256 EUR \\
\hline Money-back guarantee & 260 days & 356 days & 2 months & 140 days \\
\hline Overall grade & 1.49 & 1.35 & 1.44 & 1.31 \\
\hline Offer available for & $9 \mathrm{~h}$ & $48 \mathrm{~h}$ & short time & $26 \mathrm{~h}$ \\
\hline Memberships remaining & 58 & 23 & 17 & 68 \\
\hline
\end{tabular}

Figure 1. Thomas' Status Update on his Playful Experiment with Spam E-mails

Play also exists in the form of documentation or presentation of real-world playfulness onto digital spaces in non-educational contexts. Wang, a third year Chinese PhD student in East Asian Studies, experimented with colored papers in her department's copy room and displayed her ability to play around with surrounding materials in one of her posts, as shown in Figure 2. Following the creation of flowers by using colored paper, Wang extended her play in online digital space by depicting her 'artwork' in multimodal shape. She exhibited her literacy by framing her post in a playful language indicating her enjoyment of the process. 
See you can tell how many color papers I steal from department's copy room! lol

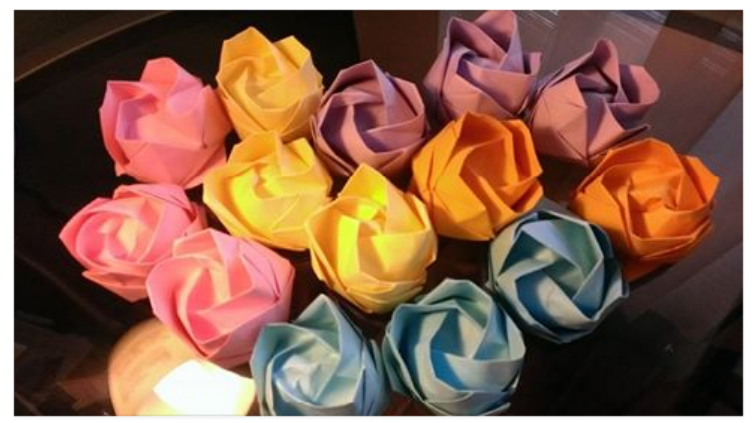

Like - Comment - Share

B 6 people like this.

Figure 2. Wang's Photo Sharing on her Play with Colored Papers

A common demonstration of Play observed was the frequent use of memes. Memes, humorous pieces of content in various media formats that rapidly spread on the Internet, were among the playful content that were shared by IGSs, as shown in Figure 3. While the action of sharing a meme may not necessarily be within the scope of Play as an NML, the ways the memes are re-shared and recontextualized for a different audience can be interpreted as the practice of Play in social media space.
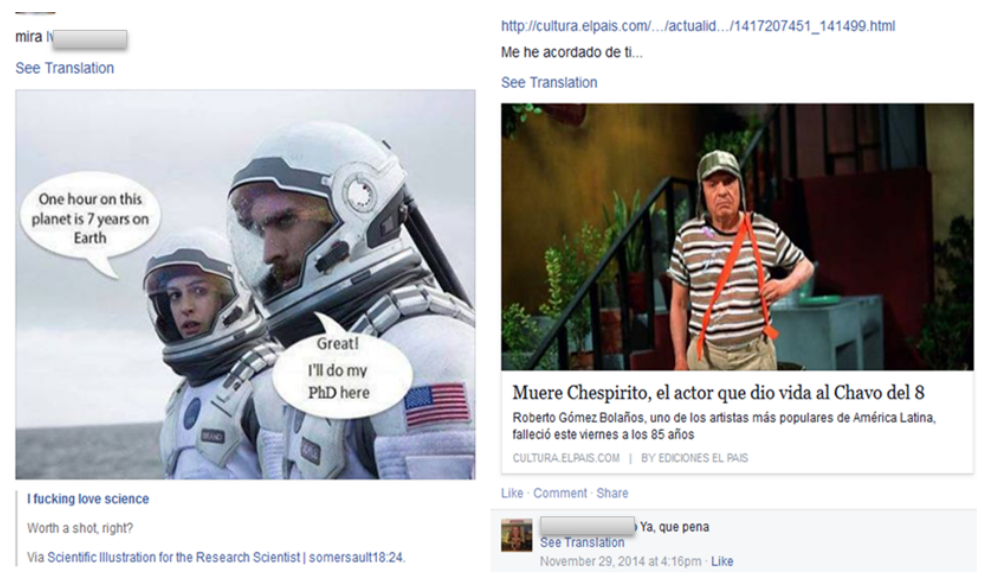

Figure 3. (Left) Isabel's Meme Post, (Right) Mariela's Friend Sharing the Death News of a Beloved Actor

Simulation is defined as "the ability to interpret and construct dynamic models of real world processes" (Jenkins et al., 25). Individuals are expected to represent and manipulate information in powerful new ways in order to be considered to have Simulation literacy. The mean score of IGSs' Simulation literacy was only 3.40, the second lowest score among NMLs. Carlos, a fifth year Costa Rican PhD student in Linguistics, shared a video which can be considered 
as Simulation literacy, since Carlos is taking advantage of a video Facebook introduced called "A Look Back." Developed by Facebook for its users, the video compiled a collection of Carlos' photos and other life event experiences. As shown in Figure 4, Carlos made use of a powerful media to represent his activities and photos by customizing an existing medium afforded by the SNS itself. Furthermore, he also employed Negotiation by traveling across different communities and Networking by addressing various audiences in a single post. It can be seen in the figure that both English and Spanish texts that were efficiently used to introduce the video are equivalent with the exception of the subject of the sentences. This is a fine example of what we may call Translingual Navigation as well. While Carlos specifies a name (Arthur) in his English text, his subject is "a professor of mine" in the Spanish version, thus indicating his familiarity with his audience's recognition/knowledge of his professor.

\section{As @A said, "cheesy and sentimental", but so many moments here made me smile. // Como dijo un profesor mío, está "un poco polo y sentimental", pero hubo muchos momentos aqui que me hicieron sonreir.}

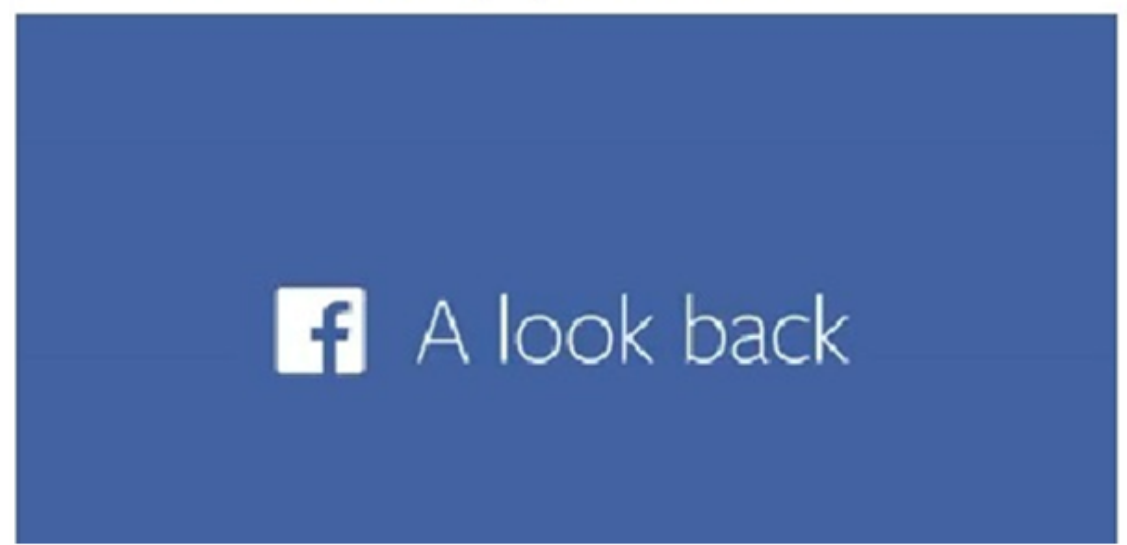

Figure 4. Carlos' Sharing of Facebook's “A Look Back” Video

A second example of Simulation was observed in the form of dealing with a different type of information. Jiao, a third year Chinese $\mathrm{PhD}$ student in Computer Science, shared the post in Figure 5 at a time when he was on a calorie watch. He exhibited his Simulation literacy by dealing with larger bodies of information (such as type, quantity and calorie of different types of food) and experimenting with complex configurations of data. While SNS was not the medium affording him using that literacy, the SNS offered a space for him to make use of the meaning potential of the application he used. Thus, he skillfully made use of another medium, a weight watch application, and then transferred this information onto the SNS. The act of transfer showed that he also had Transmedia Navigation, a literacy which requires users to successfully navigate across different media platforms. 


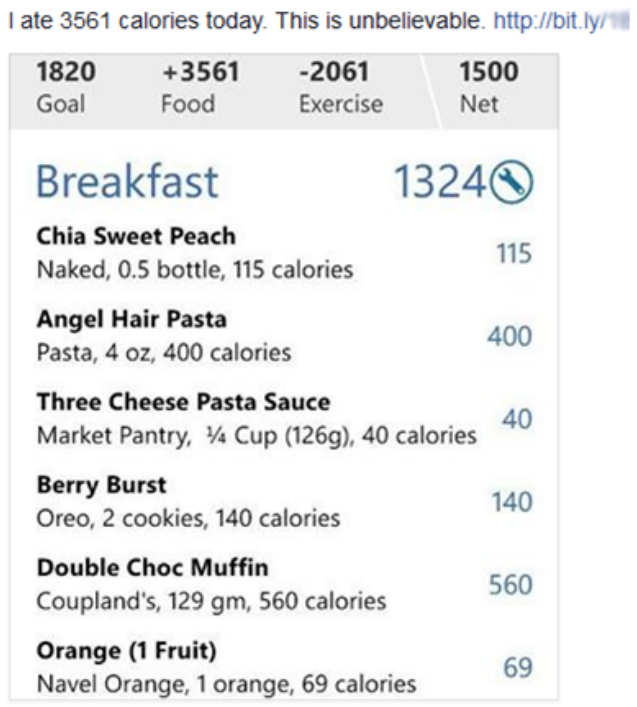

Figure 5. Jiao's Post Representing his Daily Calorie Count in Detail

The definition of Performance is given as "the ability to adopt alternative identities for the purpose of improvisation and discovery" (Jenkins et al., 2006, 25). Adopting Gee's (2003) concept of Projective Identity in their work, Jenkins and his colleagues argued that projecting "one's values and desires into a virtual character" (Gee 2003, 55) allowed game players to strongly identify with the character. Based on this definition, a successful Performance in social networking contexts can be interpreted as a skillful use of digital resources and practices to demonstrate various aspects of the (projected) identity. Therefore, it is argued that IGSs' efficient participation in digital social networks requires performances that are conducted by means of both textual and multimodal practices afforded by SNSs. The mean score of Performance of IGSs had been found as 3.70, which was the fourth lowest score of all literacies.

Figure 6 shows three different images, which were used as profile pictures by three separate participants of this study. The first image used by Mihret, a second-year Ethiopian Master's student in Water, Society, and Policy, is a painting of Catherine Hamlin, a well-respected figure in Ethiopia and known for her medical contributions to the country's women. The picture in the middle used by Elif, a fourth-year Turkish PhD student in Gifted Education, is a photo of Mustafa Kemal Ataturk, the founder and the first president of the Republic of Turkey. The picture in Elif's profile is dated as November 9. Taking the 10-hour time difference between U.S. and Turkey time zones into account, it is clear that Elif made this photo her profile picture for the death anniversary of Mustafa Kemal Ataturk, which is commemorated on November 10 every year. Finally, the picture on the right is a graphic image of Pakistani flag that Zahra, a third-year Pakistani PhD student in Applied Linguistics, used as her profile picture. It can be argued that a projected national identity is performed through the adoption of values associated with home countries in these cases. The national references are quite apparent to respective audiences of these students. While Mihret's choice was a figure who is well-known for her connection and contribution to Ethiopia, 
Elif's selection was the founder of modern Turkey and her timing was also part of a collective performance through which she became part of a national event at a time she was in the United States. Zahra, on the other hand, projected her Pakistani identity by using a white star and crescent moon on a green background, the Pakistani flag. The profile picture is among the common digital spaces for SNS users to display themselves or content associated with them. Therefore, they are interpreted as means for IGSs to present their projected identities in digital platforms.
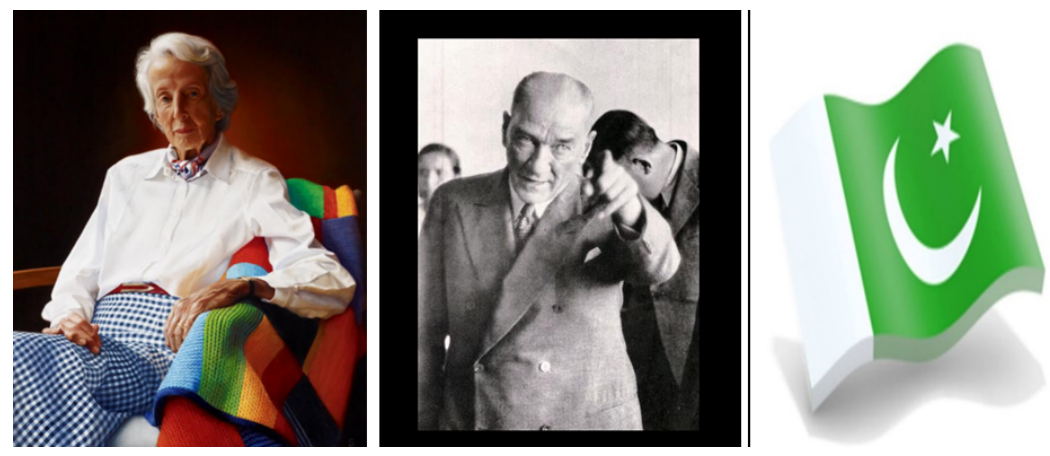

Figure 5. Profile Pictures: (Left) Mihret's profile picture, a painting of Dr. Catherine Hamlin, (Middle) Elif's profile picture, a photo of Mustafa Kemal Ataturk, (Right) Zahra's profile picture, a graphic image depicting Pakistan's flag

\section{Appropriation, Judgment, and Multi-tasking}

Appropriation is defined as "the ability to meaningfully sample and remix media content" (Jenkins et al., 2006, 32). The use of Appropriation, which has the lowest score of all literacies in this study $(\mathrm{m}=3.34)$, involves a combination of different media and giving them a new purpose in digital contexts. Nissa, a thirdyear Thai PhD student in Applied Linguistics, used the picture in Figure 6 as her cover photo in her social networking account. The photo is a collage of three different sunset photos that are taken by Nissa at different times and is accompanied by the words of "Love," "Tucson," and "Sky." It is clear that Nissa's collage represents her love of the sunset skies of the city where she resides in the U.S. The words and the picture selections are also indicative of her meaningful sampling and remixing: The "Love" is used under a sunset capture which is shown inside a heart shape formed with hands, the "Tucson" accompanies a photo of the city's mountains and the sky, and the "Sky" is used under the picture in which lies a dramatically red-colored sky with the silhouettes of trees. 


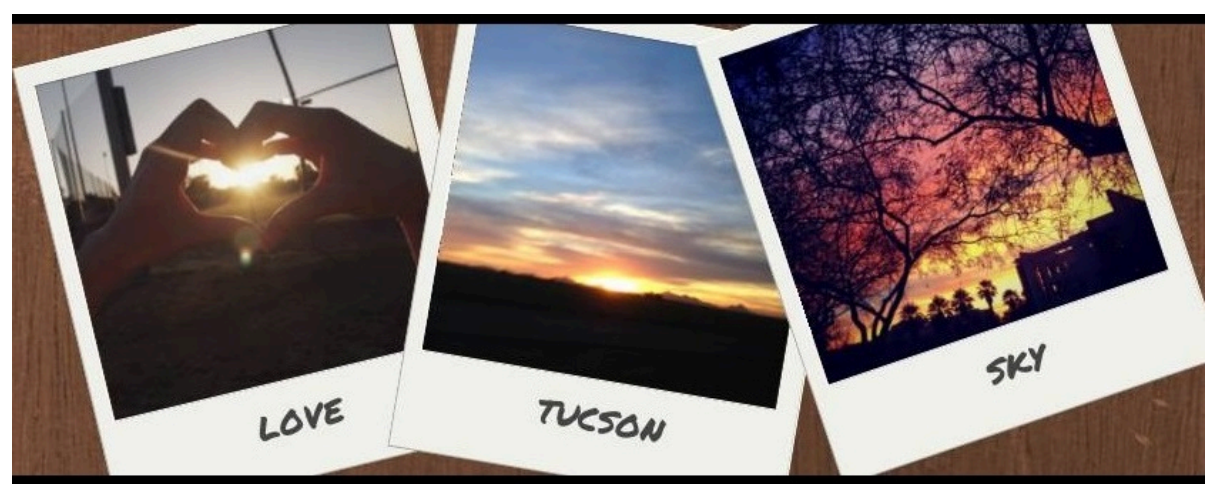

Figure 6. Nissa's Photo Collage as her Cover Photo

Appropriation is part of the re-semiotization process, which "involves an entirely new set of contextualization conditions and thus results in entirely 'new' semiotic process, allowing new semiotic modes and resources to be involved in the repetition process" (Blommaert and Varis, 2014, 8). Nissa engaged in resemiotization practice here by creating a new semiotic mode through the modification of multimodal resources. It is also seen that, as Jenkins and his colleagues pointed out, Appropriation involves both analysis and commentary. Nissa made close analysis of the existing cultural reservoir (local sunsets in this case) and showed her appreciation by repurposing the three photos taken at different times. When Nissa was asked about her cover photo during the interview, she responded by saying:

I was learning an editing software as part of a class I took when I posted this and the software offered various options for designing cover photos on Facebook. (Interview with Nissa)

As a result, she employed both Transmedia Navigation for switching between a media software and SNS, and Appropriation for meaningfully repurposing an existing material.

In another example, Nara, a first-year Indonesian Master's student in English Language and Linguistics, can be seen engaged in a digital practice where she deployed a number of NMLs together Figure 7 shows her use of Appropriation by creating her own Wikipedia page using a SNS application and displaying her cultural knowledge of the Grammy Awards while critically framing her post. Her textual presentation of the digital activity included both analysis and commentary that are parts of successful Appropriation. 
...hottest and most influential... doesn't have singing career but receive Grammy for best song and album... Fantastic! $\Theta$

But yeah, to some degree, everyone of us is an actress/actor: :

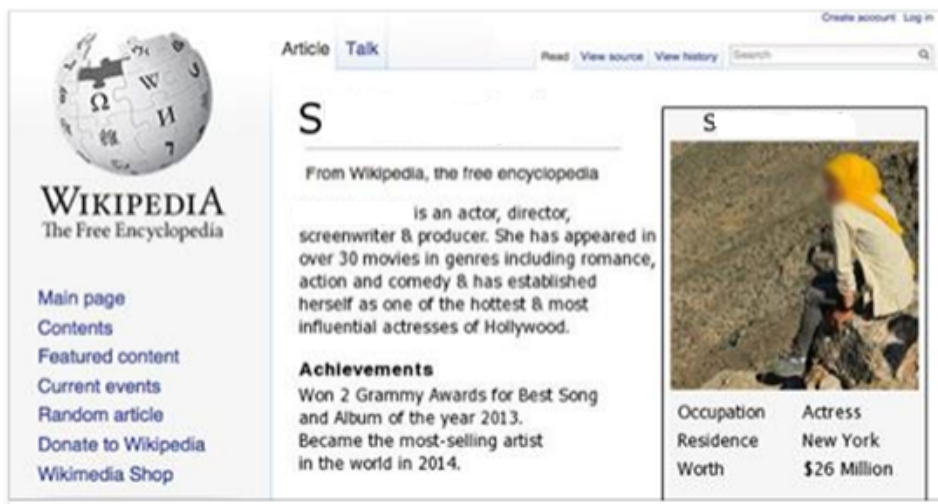

Make Your Own Wikipedia Page

Siti is now listed on Wikipedia. Click to make your own amazing Wikipedia page.

FIZZ-APPS.PW

Figure 7. Nara's Post on Creating her own Wikipedia Page

Ahmed, a fourth-year Egyptian $\mathrm{PhD}$ student in Applied Linguistics, deployed Judgment in one of his digital practices Figure 8 shows a shared news piece regarding a story about a man who was arrested outside of a mosque for being armed with explosives. While the act of sharing the story from another media outlet was indicative of Transmedia Navigation, the way he framed the post showed his Judgment. Critically questioning Fox News as a reliable news source, he distinguished two different media outlets over a potential way of presentation of a story. Ahmed, who has a self-reported strong Muslim identity, had similar digital practices where he made use of his Judgment by questioning the credibility of various media sources. The employment of Judgment allows individuals to index themselves as legitimate members of their online and offline communities as the critique itself can function as a marker of identification.

\section{Have not seen that on Fox News!}

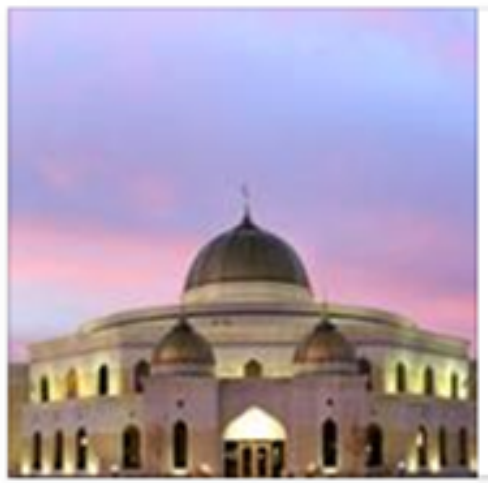

\section{Man arrested with bomb outside of mosque}

A man allegedly armed with explosives outside of one of the country's largest mosques in Dearborn, Michigan was arrested this past week.

\section{SOA.LI}

Figure 8. Ahmed's Critical Post on Credibility of News Sources 
Defined as "the ability to scan one's environment and shift focus onto salient details on an ad hoc basis" (Jenkins et al., 2006, 34), Multi-tasking can be interpreted as a literacy of practicing both digital and face-to-face tasks at a given time. For many of the participants of this study, connecting to their digital social networking account itself involved Multi-tasking as they expressed that they often used SNSs in between different activities or on the move. However, the mean score for this literacy was only 3.70, being among the lowest. In SNS context itself, Multi-tasking can be observed through individuals' participation in live events. In Figure 9, Estella, a second-year Spanish Master's student in Hispanic Studies, can be seen sharing a photo of her television screen on which Golden Globes Awards was being aired. As indicated by her text on the post, she posted this picture while watching the Golden Globes Awards live on television. She also displayed Transmedia Navigation as she posted the photo to her Instagram account first and then re-shared with her audience on Facebook.

\section{Golden Globes live!! \#tinafey \#goldenglobes \#oitnbhastowin \#houseofcards}

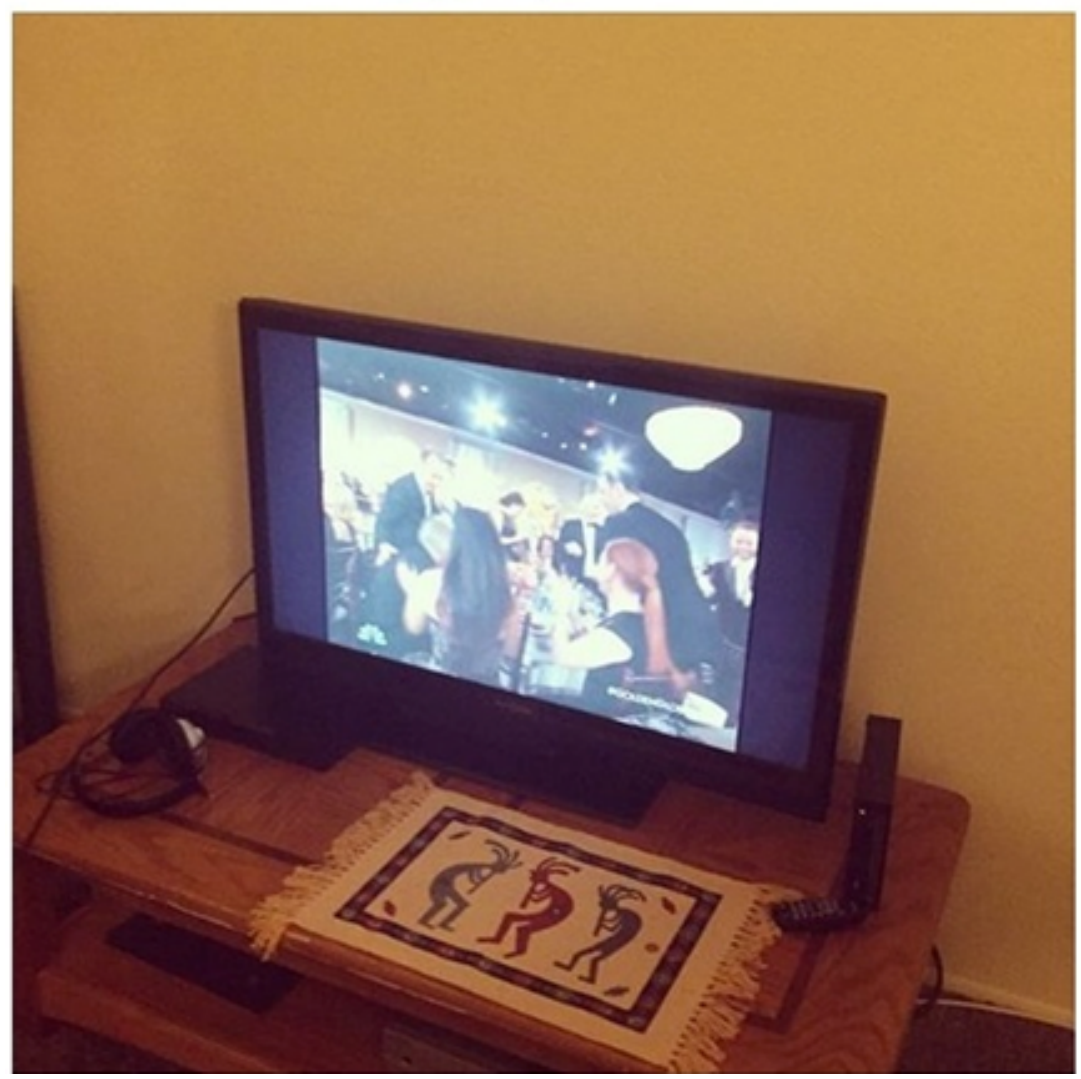

Figure 9. Estella's Post on Watching the Golden Globes Live

Similarly, Jiao, a Chinese student pursing a $\mathrm{PhD}$ degree in Computer Science, shared his location and a photo with his audience by using the popular geo-location application of Swarm, thus performing Transmedia Navigation and Multi-tasking as he also used his smartphone to take a photo and share it. He was 
engaged in a \#geocache activity, an outdoor recreational activity where individuals search for a waterproof container that often has a logbook and small item called cache. While searching for a cache, he warned himself to be cautious of being hurt or having a flat tire as his earlier posts revealed that he was riding a bicycle. It is clear that Jiao responded to his environment by scanning his cache, yet he was simultaneously engaged in multiple stimuli. As in these examples, multi-tasking literacies allow individuals to traverse simultaneous online and offline spaces at any given moment while they engage in several practices.

\section{Distributed Cognition, Collective Intelligence, and Transmedia Navigation}

Distributed Cognition ( $m=3.76,6^{\text {th }}$ highest score), Collective Intelligence $\left(\mathrm{m}=4.06,3^{\text {rd }}\right.$ highest score $)$, and Transmedia Navigation $\left(\mathrm{m}=4.03,4^{\text {th }}\right.$ highest score) are respectively defined by Jenkins et al. (2006) as "the ability to interact meaningfully with tools that expand our mental capacities" (37), "the ability to pool knowledge and compare notes with others towards a common goal" (39), and "the ability to follow the flow of stories and information across multiple modalities" (46).

Distributed Cognition involves the successful use of information appliances or devices that augment individuals' cognitive abilities. Distributed cognition as an NML can be seen in different forms in online social networks since SNSs have a variety of technological features that afford users the ability to take interactions with their audiences beyond textual expressions.

As pointed out by Jenkins and his colleagues, Distributed Cognition is not only about technologies; it also requires reaching out to experts in a specific topic by means of video conferencing, instant messaging, or e-mails. As seen in Figure 10, IGSs exploited the networking affordances of SNSs by using it as a medium to ask for the help of experts in a particular area. In Figure 10, Carlos is seen asking his linguist colleagues about the dress code at the Linguistic Society of America Conference. While asking for help, Carlos opted to use English only

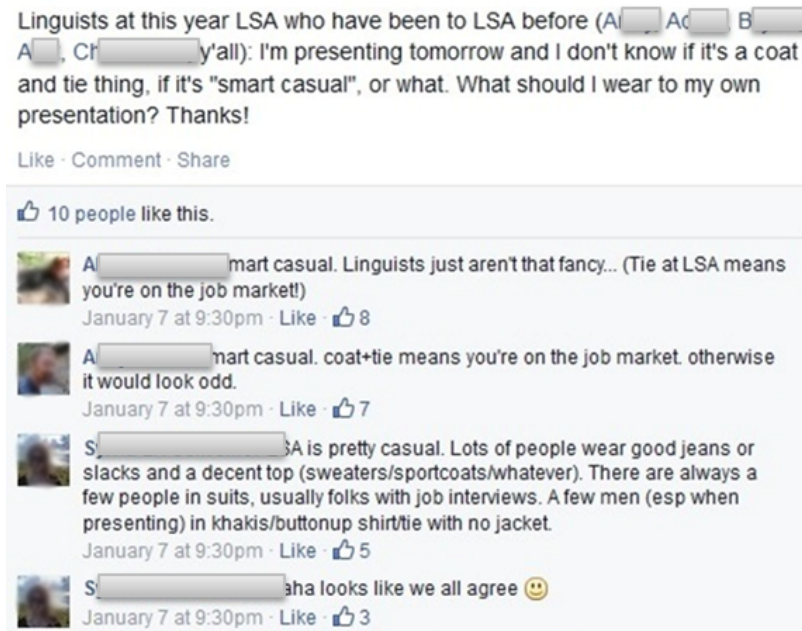

Figure 10. Carlos' Question Regarding Dress Code at a Conference 
(unlike many of his other posts where he used both Spanish and English). He narrowed his audience down to the experienced linguists and tagged some of his professors, which exhibited his awareness of locating the experts in the area he needed help with. The "likes" and the comments triggered by the post indicated that Carlos successfully aligned with linguists in his network as he found experts within his distributed social networking environment. In comparison with other media for reaching experts such as e-mail or phone, SNSs have comparatively more power to present opportunities for individuals to display their distributed cognition literacies.

Collective intelligence, a term borrowed from French cybertheorist Pierre Lévy, is similar to Distributed Cognition and there are overlaps between these two literacies. In Carlos' update in Figure 10, Carlos displayed distributed cognition while his network participated in the process where they formed a collective intelligence by creating a knowledge pool. In Figure 11, Zahra can be seen contributing to the information pool of her social network by warning them about her recent experience with an e-mail she received. This example is in line with Levy's (2000) argument of everyone knowing something and nobody knowing everything, as Zahra is seen helping others in her community. Collective intelligence is often more prevalent among the groups that are gathered around a special interest or affiliated under common interests such as The Battlestar Galactica franchise or The Lord of the Rings trilogy.

\section{Hi all,}

Please do not open any emails with the content "happy new year". It is a virus

for hacking and helps hackers get into your email accounts. Apparently I

opened the content being thoughtless and my emails are acting weird.

Stay safe!

Figure 11. Zahra's Status Update Warning her Audiences against Hackers

Transmedia navigation, which necessitates efficient use of multiple media resources and sites, is one of the most commonly exhibited NMLs in SNSs. In Figure 12, two posts of Jiao which have the same text and photo can be seen shared in his Twitter and Facebook accounts. Jiao's post is especially remarkable as his father sent him a photo in which his father's decoration of yogurt with "National Day" text was visible. After receiving this photo from China, he projected his national identity by conveying the image to his followers on Twitter, and sharing with his audience on Facebook. Thus, successful use of transmedia navigation made a local product globalized through re-contextualization and allowed Jiao to experience a simultaneous presence in multiple sites. This is a clear example of the role and importance of such NMLs for the circulation of cultural products from one space to other culturally and linguistically diverse sites. The possession of such literacies helps IGSs position themselves as 'authentic' members of their home communities and a contributing member of wider networks they are affiliated with. 


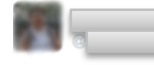

Oct 01 is National Day of the People's Republic of China. My father decorates yogurt with "National Day" text.

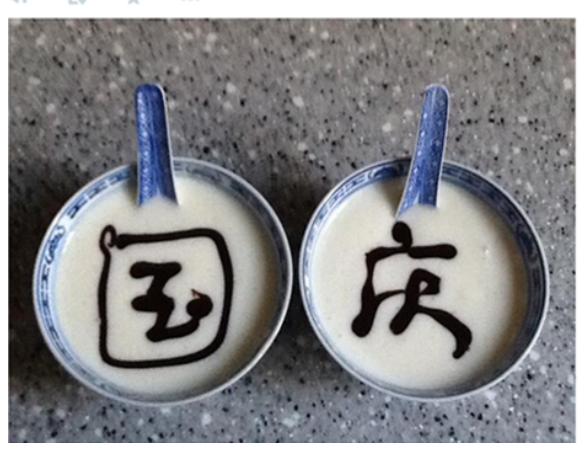

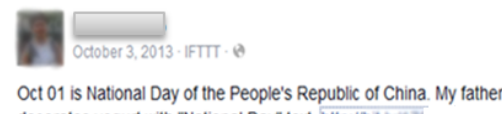

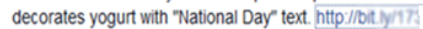

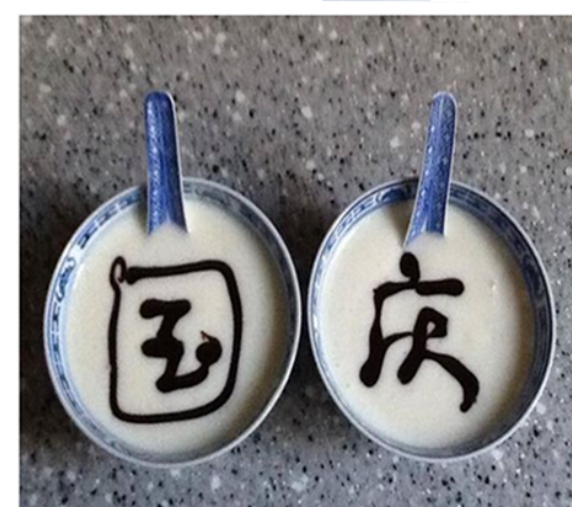

Figure 12. Jiao's National Day posts on his Two Different Accounts

The scope of Transmedia Navigation is not limited to the transfer between technological tools. This literacy also involves dealing with the flow of information from multiple resources. Gloria, a third-year Mexican PhD student in Arid Lands Resources, was observed following the news story of a mine spill in Mexico from multiple media outlets including local (Cronica from Mexico) and global ones (BBC Mundo), as Figure 13 shows. Gloria's transmedia navigation included the level of simple recognition (she identified the same content across multiple sources), the level of narrative logic (she understood how the story was communicated in dispersed media content), and the level of rhetoric (she expressed her ideas within her SNS account in different ways using Spanish and English). During the interview, she mentioned how knowing her audience led to the navigation of multiple platforms and employment of certain linguistic choices:

I actually have a lot of friends who speak Spanish, so it is kind of easier to that if you are in this region [Southern Arizona]. I have at least 10 American friends who speak Spanish as well. So, they are like the bridges of information. I can share those [resources] with them and I am pretty sure they will talk about it to their American friends who do not speak Spanish. (Interview with Gloria)

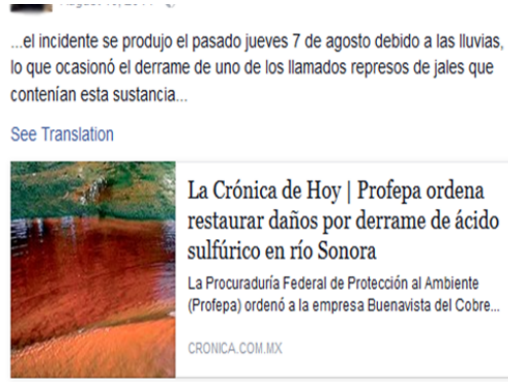

...el incidente se produjo el pasado jueves 7 de agosto debido a las lluvias lo que ocasionó el derrame de uno de los llamados represos de jales que contenian esta sustancia.

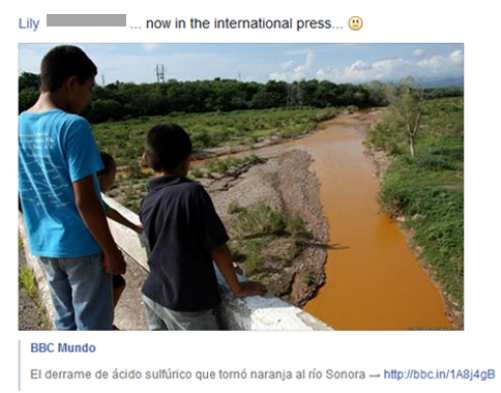


Figure 13. Gloria's Posts Show that she Follows the Mine Spill from Different Sources

\section{Networking and Negotiation}

The last two of the NMLs are Networking $\left(\mathrm{m}=3.73,7^{\text {th }}\right.$ highest score) and Negotiation $(\mathrm{m}=4.44$, the highest score). Networking emphasizes being able to search for, synthesize, and disseminate information, while Negotiation focuses on the capacity to be able to travel across different communities and respect diverse norms present in online contexts. Even though these two literacies are listed separately, they both require an ability to understand relations between information and the navigation of these resources across different social communities. Figure 1, displayed above, which illustrated Michael's playful experiment with spam emails he received, is a good example of Networking literacy in Jenkins and colleagues' original definitions. However, this literacy can be expanded beyond the synthesis of information as it also requires an ability to successfully address one's networked audience on SNS. Two examples in Figure 3 show how participants make use of their Networking literacies in SNS context. The post on the left was shared by Isabel, a third-year Chilean PhD student in Teaching and Teacher Education, and the post on the right was shared on the wall - i.e. SNS home page - of Mariela, a second-year Spanish Master's student in Legal Studies. Isabel shared a widely circulated meme inspired by the sciencefiction movie of Interstellar, in which a group of explorers discover a new planet where gravitational anomalies cause time to move significantly slower. Even though she specifically addressed her husband, who had recently received his $\mathrm{PhD}$ degree, by embedding the text "Look [the name of her husband]," a total of 15 people reacted to her post by "liking" it. In the second post, a friend of Mariela's wrote "I thought of you" in Spanish and shared the news of the death of the main actor of the popular Mexican show El Chavo del 8, which was popular in Spain as well. When asked about this, Mariela expressed that both she and her friend used to watch this show and her friend knew that she loved this show. In both cases, it is observed that individuals found and disseminated information with a particular audience, thus using re-semiotized resources as mediums to solidify relationships within their networks. Both of the individuals understood the dynamics of their network and managed to find ways to network with either a group of colleagues to whom they relate, or a close friend by successfully filtering and repurposing the information they found.

Negotiation, which was commonly found across the data of the participants, requires going beyond information dissemination and involves traveling across different communities in one's network and respecting alternative norms. Yeong, a second-year Korean Master's student in Communication, provided a good example of this literacy as seen in Figure 15. Yeong updated her status in both English and Korean at the end of her first semester at graduate school. Although briefly shared her enthusiasm of "being done" in the semester in English, she wrote the following text in Korean: 
Just finished grading my students' exams as my last task of this semester and I'm finally done! This 3rd semester of MA was seriously never ending! Now it's time to recover, sleep, take care of my skin and fix my diet!

\section{Never had such along semester! Finally I'm done done for real!!! 방금 전 아이들 시험 채점을 마지막으로 이번학기가 진짜 끝이났다!!!!! 후아 진짜 지독하게 안끝나던 이놈의 석사 3 학기. 이제 잠 보충, 피부관리, 식단개선 할시간 ***}

Figure 15.Yeong's Status Update Regarding the End of the Semester

When Yeong was asked about the difference, she explained:

It is typical for Korean girls to take care of themselves and their skin after having an exam period in which they were all tired, did not sleep or eat well! (Interview with Yeong)

It is seen that Yeong was aware of the audience in her network and displayed her awareness by making certain linguistic choices and she elaborated her post more in Korean in order to address her audience in Korea better, thus employing Negotiation.

In Figure 16, Elif's status update regarding the Christmas and holiday time in the United States can be seen. Displaying her cultural awareness in the language of the audiences in her network she addressed, Elif also exhibited Negotiation by recognizing the existence of various groups in her community and showing respect to people following different norms than hers. The number of likes she received $(\mathrm{n}=15)$ may be interpreted as her successful navigation across two different communities in her American network.

\section{December 24, 2014 at 2:16pm - Tucson, AZ - e}

Merry Christmas to those who celebrate it, and happy holidays to those who don't:)

Figure 16. Elif's Status Update Regarding Christmas and Holiday Time

\section{Discussion}

This study examined the social media literacy practices of multilingual students through the theoretical lens of New Media Literacies and Participatory Culture frameworks. Following the collection of data consisting of an online survey, semi-structured interviews, and social media data of the participants, the quantitative and qualitative analyses of the data revealed that international graduate students (IGSs) engage in various social media literacy practices through 
the employment of multimodal tools and resources afforded by social networking sites (SNSs).

The findings of the study show that IGSs use different types of SNSs and instant communications technologies, Facebook being the most common. One of the widely reported purposes of Facebook use by IGSs is to communicate with people from their home countries (including family members and friends), and with people from different countries including the friends they made in the host country (U.S.). Sustained contact with the home country is considered a requisite for the maintenance of social ties and affiliation with one's culture of origin (Suarez-Orozco 2001), and these findings show SNS is a valuable medium for IGSs to do so. Past research as reported by Brandtzæg (2012) and Zhang and Leung (2014) indicates that SNS use can facilitate social support and has the potential to extend existing levels of social contact. Considering that the research on IGSs' socialization into their new environments include challenges resulting from separation from family, social and cultural adjustment $(\mathrm{Ku}$, Lahman, Yeh and Cheng, 2008), and limited social network opportunities especially within the first few months (Hirt and Muffo, 1998), SNS can play a role for IGSs to overcome some of these challenges since students may maintain their older and stronger ties with home country audiences through SNSs.

An important finding of the study provides support for Jenkins et al.'s (2006) Participatory Culture framework, which argues that the successful participation of individuals in new media sites can be achieved through the practice of certain new media literacies (NMLs). Regardless of mean score differences across participants' NMLs, individuals are observed that they successfully engage in participatory SNS spaces and perform a wide array of digital practices by employing various literacies. Following the idea behind Blommaert's (2010) 'truncated repertoires', which is defined as "highly specific 'bits' of language and literacy varieties combine in a repertoire that reflects the fragmented and highly diverse life trajectories and environments of such people" (8), it is argued that while possessing higher NMLs is parallel to the successful participation in new media spaces, "truncated literacies" do not prevent individuals to meaningfully engage in online participatory sites. To draw attention to the importance of NMLs in new media spaces, it is suggested that the concept of "truncated repertoire" should entail NMLs by including additional symbolic, extra-linguistic competences. As argued by New London Group (1996), negotiation of social and cultural contexts and communities in today's globalized spaces requires communication ability across a multiplicity of media, modes and linguistic forms. What we see in the examples shared above and in other digital practices of IGSs is that students use both linguistic and nonlinguistic resources to negotiate complexities of their networks, even as their literacies are partial or truncated. As the employment of linguistic and new media practices are intertwined in digital participatory contexts, the conceptual umbrella of "truncated repertoire" may be useful especially when investigating the role of such repertoires in successful participation in new media sites.

This study contributes to the scholarly discourse introducing the Participatory Culture framework in a specific participatory web space, Facebook. 
Since different environments may afford distinct multimodal tools, activities and literacy practices (Ahn 2013), and NMLs are developed with a wide variety of new media spaces in mind, the reinterpretation of Jenkins and colleagues' NMLs is important. The present study joins Ahn's (2013) work, in which she analyzed NMLs by using social learning analytics and behaviors in these spaces. She concluded that Facebook behaviors were most related to Networking, Negotiation, Appropriation, and Transmedia Navigation, while Play, Judgment, and Transmedia Navigation were not related. Based on the fine-grained qualitative analysis of a good number of SNS data, one of the findings of the current study is the observation of overlapping quality of NMLs in the sense that multiple literacies can be employed by an individual at a certain time, and some of the literacies themselves overlap when interpreted in SNS context.

Therefore, an initial reworking of some of the literacies in social media context is suggested. In the current research, while some of those literacies were identifiably equitable, some of them were redistributed across other literacies and new categories are recommended. The adapted version, which may be referred as "Social Media Literacies" or "Social Network Literacies", is largely based on Jenkins' work and needs further examination through which some changes and additions could be made:

Play: "The capacity to experiment with one's surroundings as a form of problem-solving" (Jenkins et al. 2006, 22). This definition is the same as original version.

Simulation: "The ability to take advantage of technological tools afforded, meaningfully interact with them, and represent/manipulate information". This literacy is partly merged with Distributed Cognition from Jenkins' work, and the definition is expanded.

Performance: "The ability to display various aspects of the identity for selfpresentation and impression management and to adopt fictive identities for the purpose of improvisation and learning". This definition is expanded to include identity and impression management in SNSs.

Appropriation: "the ability to meaningfully sample and remix media content (Jenkins et al. 2006, 32) and to search for, synthesize, and disseminate information" (49). This literacy is merged with the definition of Jenkins'

Multi-tasking: "the ability to traverse simultaneously between offline and SNS contexts". The meaning of this literacy is preserved, however, a new definition is suggested.

Judgment (Negotiation): "the ability to evaluate the reliability and credibility of different information sources" (Jenkins et al. 2006, 43). Two literacies (Judgment and Negotiation) are merged here, because Negotiation is interpreted in terms of the negotiation of resources rather than audiences or communities.

Transmedia Navigation: "the ability to follow the flow of stories and information across multiple modalities" (Jenkins et al. 2006, 46). This definition is the same as original version.

Networking: "the ability to travel across diverse communities, discerning and respecting multiple perspectives, and grasping and following alternative norms (Jenkins et al. 2006, 52), appropriately recognizing and addressing diverse 
audiences and cultures in the network". Due to the overlap of Networking with Negotiation literacies, the definition of Negotiation is re-interpreted as Networking literacy and expanded. It is mainly because this literacy involves engagement and interaction with audiences rather than resources.

Collective Intelligence: "the ability to pool knowledge and compare notes with others towards a common goal (Jenkins et al. 2006, 39), and effectively seek help from experts in the network". The original definition is preserved, and it is combined with relevant aspects of Distributed Cognition.

Trans-genre and Translingual Navigation: "the ability to follow and produce content across multiple genres and linguistic elements." This literacy is newly suggested since multiple types of genres co-exist in participatory spaces, thus certain literacy practices are required to navigate across several genres and a culturally and linguistically diverse environment.

Another important finding of the study, which clearly shows the role of NMLs for participation in SNS, is the functions that NMLs serve when they are employed. With the help of these practices, products are circulated from one place to another (Transmedia Navigation), multimodal resources are modified and resemiotized (Appropriation), expertise is shared (Collective Intelligence), an awareness for multiple audiences is raised (Networking) and various aspects of identities are projected (Play, Performance, Judgment). It is through such functions of NMLs that IGSs engage in a multitude of diverse practices, which help them index their affiliations with certain communities and groups. They allow users to engage with multiple resources and a networked audience to perform and transform their identities while experiencing transnational mobility, which allows for further diversification of resources and audiences in an individual's network. Thus, the current study offers contributions to the scholarly discourse on identity presentation in CMC-contexts and particularly Facebook by joining others such as Bouvier (2012); Leppänen, Kytölä, Jousmäki, Peuronen and Westinen (2013); Sharma (2012); and Thorne, Sauro, and Smith (2015).

\section{Conclusion}

The adaptation of Jenkins et al.'s (2006) participatory culture framework to social media context reveals that multilingual students possessed truncated NMLs, which facilitated their participation in online diverse spaces. By truncated, I mean that some of the literacies of IGSs (such as Negotiation and Transmedia Navigation) are found to be more refined than the others (such as Appropriation and Simulation). However, such differences do not seem to prevent multilingual students' successful participation in online social networks. Adapting Jenkins' framework in SNS contexts required a reinterpretation of some definitions of those literacies. In view of this adaptation, on which Jenkins' framework has major influence, I have proposed and presented a set of social media literacies that are essential for navigation and participation in diverse networks. Similar to NMLs but sometimes with slightly different meanings, social media literacies include Play, Simulation, Performance, Appropriation, Multi-tasking, Judgment, Transmedia Navigation, Networking, Collective Intelligence, Trans-genre and Translingual Navigation, all of which are aligned with The Core Principles of 
Media Literacy Education (National Association for Media Literacy Education, 2007) in various levels (e.g., inclusion of all forms of media, literacy practices as agents of socialization, construction of self-made images and meanings).

The current study has several limitations to take into consideration. First, the diversity of participants presented a limitation for the author as a researcher even though he was an IGS who had familiarity with various social networks and was frequently in contact with participants for linguistic and cultural clarifications. Second, the amount of SNS data was not the same for each participant since some participants were more active than the others. To remedy this limitation, both online survey and semi-structured interviews were used and participants' activities were observed in a time period which covered at least one year. Third, the number of statements used in the self-reported Likert-scale NML assessment tool was limited to 11 , meaning that one item corresponded to each literacy. Two or three statements reflecting the nature of each literacy might have provided a relatively better picture of IGSs' NML scores. This limitation was addressed through a qualitative analysis of literacy practices of individuals as suggested in the literature (Dawson and Siemens, 2014). Finally, while major social media practices of participants were examined in the study, the adaptation of the theoretical framework was mainly restricted to Facebook since it was the most commonly used SNS by the sample of this study's population.

This study also makes various contributions to the field. By shedding light on digital practices of international graduate students in SNSs, the study moves the discourses on IGSs literature forward by paying attention to these students' digital activities and how these sites can indirectly take part in IGS' experiences in the U.S. The current study complements Xu and Mocarski's (2014) work, in which it is suggested that social media offered opportunities for international students to improve their academic and cultural immersion. Furthermore, since the participants in the present study represent a great diversity, the research reveals further insights regarding the use of SNS resources by individuals of various cultural backgrounds. For future research, the presentations and performances of international students across various social media in connection with their graduate school experiences and themselves being the next generation of knowledge producers might be explored.

The investigation of NMLs in SNS contexts and re-configuration of some of the literacies also contributes to the emerging literature on new media literacies. Social Media Literacies can be employed in various literacy research traditions including not only the research with a media studies perspective but also the tradition of multiliteracies research with a perspective provided by New London Group's (1996) approach.

Pedagogically, scholarly synthesis developed as part of the present study can contribute to building practical guidelines for educators. Social Media Literacies can be employed in content and language learning classrooms in order to achieve successful participation of learners in digital contexts defined by diversity. While some of those literacies are already included as part of differentlanguage teaching curricula such as Performance in Global Simulation (Michelson and Dupuy, 2014) activities, a comprehensive list of such literacies 
can help teachers see the bigger picture and function as a guideline to understand the nature of participation in social media better. By understanding the types of social media literacies their students need, teachers can develop specific projects to develop students' literacies and "ensure that our students are skilled consumers and producers of digital media" (Fleming, 2013,377).

Considering the large number of students using social media channels, institutions and programs in the U.S. can actively administer their social media pages by sharing valuable information with students including social and academic resources on campus. Guided by the findings of the study, IGSs, especially those who may experience sociocultural adjustments in the first couple of months in the U.S., can benefit from social media to maintain their ties with their home countries or a technological tool where there is a presence of home country audience.

As NMLs of Jenkins (2006) have been interpreted specifically in an SNS context and literacies are particularly defined for SNSs, a conceptual piece needs to address the ways educators can improve learners' social media literacies. Furthermore, a new self-reported assessment tool measuring the social media literacies of learners should be developed and tested. With the help of such a tool, teachers can see the literacy levels of their students and design appropriate activities mainly targeting the literacies that need to develop most. Finally, it is crucial not to limit social media literacy practices of learners to the literacies exemplified above since the nature of online participatory spaces require the employment of various literacies in an evolving manner; certain social media outlets such as Snapchat may lead to participants' engagement in a multitude of various socio-literacy practices different from the literacies specified in the current study.

\section{References}

Ahn, June. 2013. "What Can We Learn from Facebook Activity? Using Social Learning Analytics to Observe New Media Literacy Skills". In LAK'13 Conference Proceedings, Belgium, April 2013.

Androutsopolous, Jannis. 2013. "Online Data Collection". In Data Collection in Sociolinguistics: Methods and Applications, edited by C. Mallison, B. Childs, G. v. Herk, 236-250. New York, NY: Routledge.

Blommaert, Jan. 2010. The Sociolinguistics of Globalization. Cambridge, UK: Cambridge University Press.

Blommaert, Jan, and Varis, Piia. 2014. "Conviviality and Collectives on Social Media: Virality, Memes and New Social Structures. Tilburg Papers in Culture Studies, 108.

Brandtzaeg, Petter Bae. 2012. "Social Networking Sites: Their Users and Social Implications: A Longitudinal Study". Journal of Computer-Mediated Communication 17 (4): 467-488.

Bouvier, Gwen. 2012. "How Facebook Users Select Identity Categories For SelfPresentation". Journal of Multicultural Discourses 7 (1): 37-57.

Burgess, Jean, Joshua Green, Henry Jenkins, and John Hartley. 2009. YouTube: Online Video and Participatory Culture. Cambridge, England: Polity. 
Chen, H. 2013. "Identity Practices of Multilingual Writers in Social Networking Spaces.” Language Learning \& Technology, 17(2), 143-170.

Dawson, Shane, and Siemens, George. 2014. "Analytics to Literacies: The Development of a Learning Analytics Framework for Multiliteracies Assessment". The International Review of Research in Open and Distributed Learning, 15 (4): 284-305.

Fleming, Laura. 2013. "Expanding Learning Opportunities with Transmedia Practices: Inanimate Alice as an Exemplar." Journal of Media Literacy Education 5 (2): 370-377.

Gee, James Paul. 2003. What Video Games Have To Teach Us About Learning And Literacy. New York: Palgrave Macmillan.

Glesne, Corrine. 2010. Becoming Qualitative Researchers (4th ed.). Boston, MA: Pearson.

Herring, Susan C. 2001. "Computer-mediated Discourse." In The Handbook of Discourse Analysis, edited by D. Schiffrin, D. Tannen, and H. E. Hamilton, 612-634. Malden, MA: Blackwell.

Herring, Susan. C. 2004. "Computer-mediated Discourse Analysis: An Approach to Researching Online Communities." In Designing for Virtual Communities in the Service of Learning, edited by S. A. Barab, R. Kling, and J. H. Gray, 338-376. Cambridge: Cambridge University Press.

Hirt, Joan B. and John A. Muffo. 1998. "Graduate Students: Institutional Climates and Disciplinary Cultures". New Directions For Institutional Research 98: 17-33.

Jenkins, Henry. 2006. Convergence Culture. New York: New York University Press.

Jenkins, Henry, Ravi Purushotma, Katie Clinton, Margaret Weigel, and Alice J. Robison. 2006. Confronting the Challenges of Participatory Culture: Media Education for the $21^{\text {st }}$ Century. Chicago, Illinois: The McArthur Foundation.

$\mathrm{Ku}$, Heng-Yu, Maria K. E. Lahman, Hsin-Te Yeh, and Yi-Chia Cheng. 2008. "Into The Academy: Preparing And Mentoring International Doctoral Students". Education Technology Research and Development 56 (3): 365377.

Leppänen, Sirpa, Samu Kytölä, Henna Jousmäki, Saija Peuronen, and Elina Westinen. 2013. "Entextualization and Resemiotization as Resources for (Dis)identification in Social Media." Tilburg Papers in Culture Studies, 57.

Levy, Pierre. 2000. Collective Intelligence: Man's Emerging World in Cyberspace. New York: Perseus.

Literat, Ioana. 2014. "Measuring New Media Literacies: Towards the Development of a Comprehensive Assessment Tool". Journal of Media Literacy Education 6 (1): 15-27.

Michelson, Kristen, and Dupuy, Beatrice (2014). "Multi-storied lives: Global Simulation as an Approach to Developing Multiliteracies in an Intermediate French Course". L2 Journal, 6 (1): 21-49.

National Association for Media Literacy Education. 2007. Core Principles of Media Literacy Education in the United States. Retrieved from 
https://drive.google.com/a/dicle.edu.tr/file/d/0B8j2T8jHrlgCYXVHSVJid Wtmbmc/view

New London Group. 1996. "A Pedagogy of Multiliteracies: Designing Social Futures". Harvard Educational Review, 66 (1): 60-92.

Sharma, Bal Krishna. 2012. "Beyond Social Networking: Performing Global Englishes in Facebook by College youth in Nepal." Journal of Sociolinguistics, 16 (4): 483-509.

Suárez-Orozco, Marcelo. 2001. "Globalization, Immigration, and Education: The Research Agenda." Harvard Educational Review, 71 (3): 345-366.

Thorne, Steve. 2003. "Artifacts and Cultures-of-use in Intercultural Communication." Language Learning and Technology, 7 (2): 38-67.

Thorne, Steve, Shannon Sauro, and Bryan Smith. 2015. "Technologies, Identities, and Expressive Activity." Annual Review of Applied Linguistics, 35: $215-$ 233.

$\mathrm{Xu}$, Qiong, and Mocarski, Richard. 2014. "A Cross-cultural Comparison of Domestic American and International Chinese Students' Social Media Usage." Journal of International Students, 4 (4): 374-388.

Young, Jimmy A. 2015. "Assessing New Media Literacies in Social Work Education: The Development and Validation of a Comprehensive Assessment Instrument." Journal of Technology in Human Services, 33 (1): 72-86.

Zhang, Yin, and Leung, Louis. 2014. "A Review of Social Networking Service (SNS) Research in Communication Journals from 2006 to 2011." New Media \& Society, 17 (7): 1007-1024. 